\title{
Stability of nonfouling electroless nickel-polytetrafluoroethylene coatings after exposure to commercial dairy equipment sanitizers
}

\author{
Kang Huang and Julie M. Goddard ${ }^{1}$ \\ Department of Food Science, University of Massachusetts, Amherst 01003
}

\begin{abstract}
Application of nonfouling coatings on thermal processing equipment can improve operational efficiency. However, to enable effective commercial translation, a need exists for more comprehensive studies on the stability of nonfouling coatings after exposure to different sanitizers. In the current study, the influence of different commercial dairy equipment sanitizers on the nonfouling properties of stainless steel modified with electroless Ni-polytetrafluoroethylene (PTFE) coatings was determined. Surface properties, such as dynamic contact angle, surface energy, surface morphology, and elemental composition, were measured before and after the coupons were exposed to the sanitizers for 168 cleaning cycles. The fouling behavior of Ni-PTFEmodified stainless steel coupons after exposure was also evaluated by processing raw milk on a self-fabricated benchtop-scale plate heat exchanger. The results indicated that peroxide sanitizer had only minor effect on the Ni-PTFE-modified stainless steel surface, whereas chlorine- and iodine-based sanitizers influenced the surface properties drastically. The coupons after 168 cycles of exposure to peroxide sanitizer accumulated the least amount of fouling material $\left(4.44 \pm 0.24 \mathrm{mg} / \mathrm{cm}^{2}\right)$ compared with the coupons exposed to the other 3 sanitizers. These observations indicated that the Ni-PTFE nonfouling coating retained antifouling properties after 168 cycles of exposure to peroxide-based sanitizer, supporting their potential application as nonfouling coatings for stainless steel dairy processing equipment.

Key words: nickel-polytetrafluoroethylene, nonfouling coatings, heat exchanger, dairy processing
\end{abstract}

\section{INTRODUCTION}

Accumulation of fouling material in thermal processing operations has a negative influence on service life, operational efficiency, and may affect microbiological

Received April 16, 2015.

Accepted May 22, 2015.

${ }^{1}$ Corresponding author: goddard@umass.edu safety (Visser and Jeurnink, 1997; Parkar et al., 2004). Heat exchanger fouling is a particular issue in dairy processing (Burton, 1968; Bansal and Chen, 2006), and therefore a great number of studies have sought to develop nonfouling coatings to reduce the accumulation of foulant on heat exchanger surfaces. Technologies such as plasma-enhanced chemical vapor deposition and ion implantation have been reported to impart significant nonfouling character, yet require high vacuum or temperature and specialized equipment typically used in the semiconductor industry (Santos et al., 2004; Rosmaninho et al., 2006). Silane and polymeric coatings offer the potential of high-throughput coating without specialized equipment but may suffer from delamination after extended exposure to thermomechanical and chemical stresses typical of food processing equipment (Forster and Bohnet 2000; Kananeh et al., 2010). Another well-studied nonfouling coating technology is the codeposition of polytetrafluoroethylene (PTFE) nanoparticles during electroless nickel and phosphorus plating to create nonfouling Ni-PTFE coatings on processing equipment (Lalande et al., 1989; Zettler et al., 2005; Dumitrascu and Borcia, 2006; Rosmaninho et al., 2007; Balasubramanian and Puri, 2009b; Barish and Goddard, 2013). Such Ni-PTFE coatings can be conformally applied to large, irregularly shaped solid supports (e.g., corrugated heat exchanger plates, spray drier nozzles) using commercially available coating facilities. Much of the prior research of Ni-PTFE surface modification methods concentrated on the development of surface modification technologies and their as-prepared nonfouling characteritistics (Santos et al., 2004; Rosmaninho et al., 2007; Balasubramanian and Puri, 2009a,b; Barish and Goddard, 2013, 2014). However, studies on the stability of such nonfouling coatings to exposure to commercial food-grade sanitizers commonly used in clean-in-place processes are limited. Barish and Goddard (2014) reported insignificant changes of Ni-PTFE coatings after extended exposure to alkali detergent; however, they suffered significant delamination after exposure to acid sanitizer. Furthermore, Zhao and Liu (2005a) suggested that the corrosion rate of Ni-PTFE coatings in hydrochloric acid solution was greater 
than sodium chloride solution. Besides alkali and acid cleaning agents, chlorine-, iodine-, and peroxide-based sanitizers are approved and commonly used sanitizers for food processing equipment (Khadre and Yousef, 2001). However, the effect of such sanitizers on the integrity of Ni-PTFE nonfouling coatings is unknown. Therefore, a need exists for comprehensive studies on the determination of nonfouling properties of coatings after exposure to different classes of sanitizers to enable translation of such nonfouling coatings research to industrial practice.

In the current study, we assessed the stability and nonfouling character of Ni-PTFE-modified stainless steel surfaces after exposure to 4 kinds of commercial food-grade sanitizers, including sodium hypochlorite, sodium dichloro-s-triazinetrione, iodine, and peroxide as active agents. Surface characteristics before and after exposure were analyzed by dynamic contact angle, surface energy, optical profilometry, X-ray photoelectron spectroscopy (XPS), and scanning electron microscopy. The influence of extended exposure to sanitizers on the nonfouling character of the Ni-PTFE-coated heat exchanger plates was quantified by processing raw milk on a benchtop-scale plate heat exchanger.

\section{MATERIALS AND METHODS}

\section{Ni-PTFE Modification}

Stainless steel sheets [316, 2B finish, medium hardness (Rockwell B93), with thickness of $0.61 \pm 0.07 \mathrm{~mm}$ ] were purchased from McMaster-Carr (Robbinsville, NJ). The sheets were cut to pieces with the area of 48 $\mathrm{cm}^{2}$ to serve as benchtop scale heat exchanger plates. The nonfouling Ni-PTFE coating was applied by electroless plating as described previously (Barish and Goddard, 2013, 2014). Briefly, coupons were cleaned in an alkali detergent (Cohler Enterprises Inc., Baltimore, MD) for 5 min at $89^{\circ} \mathrm{C}$, followed by electro-cleaning in alkali detergent $\left(82 \mathrm{C}, 2 \mathrm{~min}, 0.11 \mathrm{~A} / \mathrm{cm}^{2}\right.$ ) and rinsing in copious deionized water. Cleaned coupons were subjected to a Wood's nickel strike $(5 \mathrm{~min})$ to introduce a seed nickel layer, followed by electroless nickel plating $\left[60 \mathrm{~min}\right.$ at $85^{\circ} \mathrm{C}$ in high-phosphorous electro- less nickel bath (MacDermid Inc., Denver, CO)], and finally electroless nickel-PTFE plating, in which PTFE nanoparticles (MacDermid Inc.) are incorporated in the high-phosphorous electroless nickel bath at a concentration of $10.5 \%$ (wt).

\section{Food-Grade Commercial Sanitizers}

All 4 kinds of commercial food-grade sanitizers were purchased from Ecolab (St. Paul, MN). The dilution concentration of cleaning solution and operation conditions of cleaning cycle were selected according to the recommendations of the supplier, as shown in Table 1. The 4 sanitizers used in our study included: (1) Eco-San chlorine sanitizer (Ecolab Catalog No. 13979), composed mainly of sodium hypochlorite; (2) Apex solid chlorine sanitizer (Ecolab Catalog No. 14821), composed mainly of sodium dichloro-s-triazinetrione; (3) Mikroklene iodine sanitizer (Ecolab Catalog No. 14639), composed mainly of iodine and phosphoric acid; and (4) peroxide multisurface sanitizer (Ecolab Catalog No. 6100296), composed mainly of peroxyacetic acid and hydrogen peroxide. The solutions were renewed daily. Coupons were treated in triplicate for each of the sanitizers. To evaluate the stability of Ni-PTFE coatings after exposure to commercial sanitizers, the test coupons were soaked in each sanitizer for periods to simulate multiple cleaning cycles. Each cleaning cycle represents $4 \mathrm{~h}$ as typical for dairy processing clean-inplace procedure. A water bath was used to maintain the sanitizers at their respective temperatures according to the supplier's recommendations. At the end of 6,18 , $30,42,84,126$, or 168 cleaning cycles, the test coupons were removed from the sanitizer solution and rinsed 3 times in deionized water. Then the coupons were dried under nitrogen and finally stored in a desiccator until analysis.

\section{Surface Characterization}

Water contact angles of native and Ni-PTFE-modified stainless steel surfaces were measured using the sessile drop method (Dumitrascu and Borcia, 2006; Gao and McCarthy, 2009) on a Kruss DSA 100 Drop

Table 1. Preparation of various commercial food-grade sanitizers

\begin{tabular}{|c|c|c|c|c|}
\hline Sanitizer class & Product $^{1}$ & $\begin{array}{c}\text { Concentration } \\
(\mathrm{ppm})\end{array}$ & $\mathrm{pH}$ & $\begin{array}{c}\text { Temperature } \\
\left({ }^{\circ} \mathrm{C}\right)\end{array}$ \\
\hline Sodium hypochlorite & Eco-San chlorine sanitizer & 100 & $8.12 \pm 0.03$ & 25 \\
\hline Sodium dichloro-s-triazinetrione & Apex solid chlorine sanitizer & 100 & $6.20 \pm 0.01$ & 25 \\
\hline Iodine (contains phosphoric acid) & Mikroklene iodine sanitizer & 25 & $3.28 \pm 0.01$ & 25 \\
\hline Peroxide (peroxyacetic acid, hydrogen peroxide) & Peroxide multisurface sanitizer & 1 & $5.41 \pm 0.03$ & 25 \\
\hline
\end{tabular}

${ }^{1}$ All from Ecolab, St. Paul, MN. 
Shape Analyzer (Kruss, Hamburg, Germany). All contact angle determinations were performed at the temperature of $25.0 \pm 1.0^{\circ} \mathrm{C}$. Both advancing and receding contact angles were recorded at a water flow rate of 25 $\mu \mathrm{L} / \mathrm{min}$ and calculated using the circle fitting method (Drop Shape Analysis software version 1.91.0.2, Kruss). A total of 9 scans were performed for each evaluation (3 measurements taken at separate spots on 3 individual samples).

Surface energy was quantified using a Neumann model in which advancing contact angles of 4 test liquids are recorded, including HPLC water $(72.8$ $\mathrm{mN} / \mathrm{m})$, glycerol $(64 \mathrm{mN} / \mathrm{m})$, formamide $(58 \mathrm{mN} / \mathrm{m})$, and ethylene glycol $(48 \mathrm{mN} / \mathrm{m}$; Combe et al., 2004; Mittal, 2006). The glycerol, formamide, and ethylene glycol were purchased from Fisher Scientific (Waltham, MA) at the highest purity available. The nonlinear relationship between the advancing value and the surface tension of 4 liquids was fitted to a Neumann model, as shown in equation [1] (Tavana and Neumann, 2007).

$$
\cos \theta=-1+\sqrt[2]{\frac{\gamma_{S V}}{\gamma_{L V}}} e^{-\beta\left(\gamma_{L V}-\gamma_{S V}\right)^{2}},
$$

in which $\theta$ is the contact angle (degree), $\gamma_{L V}$ is the surface energy of the liquid $(\mathrm{mN} / \mathrm{m}), \gamma_{S V}$ is the surface energy of the solid $(\mathrm{mN} / \mathrm{m})$, and $\beta$ is the constant $\left(\mathrm{m}^{2} /\right.$ $\mathrm{mN}^{2}$ ), respectively. The critical surface tension of the test surface was calculated as the value at which $\cos \theta$ $=1.0$.

Optical profilometry was carried out on a Zeta-20 Optical Profilometer (Zeta Instruments, San Jose, CA) to quantitatively evaluate the variations of foulant thickness. The $5 \times$ camera lens $(\mathrm{WD}=20 \mathrm{~mm}$ ) was used, and the scanning area was 4,741 $\times 3,556 \mu \mathrm{m}^{2}$. The images were analyzed by $3 \mathrm{D}$ Zdot software (Zeta Instruments). As described below, modified surfaces that had been exposed to 168 equivalent cleaning cycles were subjected to $2 \mathrm{~h}$ of simulated pasteurization of raw milk, after which the thickness of accumulated foulant was measured by optical profilometry. Three individual samples were used for each analysis, and 3 scans were performed at 3 separate regions for each sample. The results were reported as an average \pm standard deviation for a total of 9 scans.

The changes of the elemental composition on the surfaces of Ni-PTFE-modified coupons as prepared and after 168-cycle exposure to 4 kinds of commercial sanitizers were studied by XPS. A Physical Electronics 5000 series (Physical Electronics, Chanhassen, MN) XPS equipped with a monochromatic $\mathrm{Al} \mathrm{K \alpha}$ x-ray beam source was used to obtain spectra. The incident angle for the ion beams was $45^{\circ}$ from the test surface normal.
Survey scans (187.85 eV pass energy, $1.6 \mathrm{eV}$ step size) and high-resolution spectra (46.95 eV pass energy and $0.4 \mathrm{eV}$ step size) were acquired. Spectra were analyzed using MultiPak software (Physical Electronics).

To characterize the effect of each sanitizer on surface morphology, coupons were imaged without further sample preparation after 6 and 168 cycles of exposure on a scanning electron microscope (Jeol JCM-6000 NeoScope Benchtop SEM, Peabody, MA). An acceleration voltage of $10 \mathrm{kV}$ and a magnification of $10,000 \times$ were applied to acquire high-resolution images. Images are representative of 3 electron micrographs captured at random positions on each of 3 samples.

\section{Fouling Behavior}

To characterize the influence of sanitizers on the nonfouling character of Ni-PTFE-modified stainless steel, the accumulation of foulant during thermal processing of raw milk was quantified on native stainless steel, as-prepared Ni-PTFE-modified stainless steel, and Ni-PTFE-modified stainless steel that had been exposed to 168 cleaning cycles by each sanitizer. We have previously reported the design and fabrication of a benchtop-scale plate heat exchanger (bPHE) designed to simulate processing conditions in a commercial scale plate heat exchanger (Huang and Goddard, 2015). Fouling studies were performed on this bPHE system, in which test coupons served as heat exchanger plates. Raw milk was preheated to the design inlet temperature $\left(65^{\circ} \mathrm{C}\right)$ in the preheating section. After that, the milk was drawn through the bPHE unit with a flow rate of $5 \mathrm{~L} / \mathrm{h}$ and heated to the maximum temperature of $85^{\circ} \mathrm{C}$ during the simulated pasteurization. After $2 \mathrm{~h}$, the test bPHE unit was disassembled without cleaning. Test coupons were weighed individually and stored for determination of foulant thickness. The amount of accumulated foulant reported represents an average of 3 independent processing runs.

\section{Statistical Analysis}

Statistical analysis was performed by GraphPad Prism software v.5.04 (Graphpad Software Inc., La Jolla, CA). For all comparisons, one-way ANOVA $(P<$ $0.05)$ on each data set was analyzed for contact angle, surface energy, weight of fouling material, and foulant thickness.

\section{RESULTS AND DISCUSSION}

Representative photographs of native and Ni-PTFEmodified coupons as prepared and after exposure to 168 equivalent cleaning cycles by commercial food-grade 
sanitizers are shown in Figure 1. Black spots were observed on both native and Ni-PTFE-modified stainless steel coupons after exposure to sodium hypochlorite and sodium dichloro-s-triazinetrione-based sanitizers, likely a result of formation of metal oxides (Zeller and Salvati, 1994; Sharma et al., 1998). These spots were removed by rinsing in water, similar to prior reports on formation of oxides by acid exposure (Barish and Goddard, 2014). Similar black debris also presented in the cleaning solution, even after the shortest exposure time. In addition to the surface oxides, corrosion was observed on both native and Ni-PTFE-modified stainless steel coupons after even short exposure to sodium dichloro-s-triazinetrione-based sanitizer. Our results are in agreement with prior studies that have reported that chlorine-induced corrosion of stainless steel is greater at lower $\mathrm{pH}$ values (Bohner and Bradley, 1991). Indeed more corrosion was observed on both native and Ni-PTFE-modified stainless steel after exposure to the sodium dichloro-s-triazinetrione-based sanitizer $(\mathrm{pH}=6.20 \pm 0.01)$ than after exposure to the sodium hypochlorite-based sanitizer $(\mathrm{pH}=8.12 \pm 0.03)$. As the exposure time increased, the surface presented with rust-like scale, with solution color changing to yellow. As shown in Figure 1, cracks and voids were observed after exposure to 168 cycles. These results, as well as those of the fouling study reported below, suggest that Ni-PTFE coatings are not robust against chlorinebased sanitizers.

No visible differences were observed on either native or Ni-PTFE-modified coupons after 126-cycle exposure to iodine- or peroxide-based sanitizers. With increasing exposure time (168-cycle), however, some delamination was observed from Ni-PTFE-modified coupons exposed to iodine sanitizer. Whereas delamination is considered a major cause of failure in coatings (Thouless, 1991), it may be possible to reduce delamination by modifying coating protocol. Both native and Ni-PTFE-coated stainless steel retained visual properties after extended exposure to peroxide-based sanitizer.

\section{Surface Analysis}

Dynamic Contact Angle. The changes in hydrophobicity of native and modified stainless steel coupons after exposure to different commercial food-grade sanitizers were quantified by the measurement of dynamic contact angle. Advancing $\left(\theta_{\mathrm{a}}\right)$ and receding $\left(\theta_{\mathrm{r}}\right)$ angles on native and Ni-PTFE-modified stainless steel coupons after each predetermined exposure time were measured using HPLC water (Figure 2). The effects of chlorine-based sanitizers on the contact angle of both native and modified surfaces were significant and rapid, and were attributed to surface damage such as oxide formation, corrosion, and delamination. It is interesting to note that after exposure to either chlorine-based sanitizer (sodium hypochlorite or sodium dichloro-striazinetrione), the advancing contact angle of modified stainless steel coupons were lower than that of native ones. For example, the advancing contact angle values decreased to $31.0^{\circ}$ after 30 -cycles of exposure to sodium hypochlorite, a value that is $62.8^{\circ}$ lower than native stainless steel and $76.8^{\circ}$ lower than as-prepared modified coupons before cleaning. This significant increase in hydrophilicity may be a result of cracks and corrosion causing a rough, heterogeneous surface after exposure (Makamba et al., 2005; Long and Chen, 2006). It is also likely that a thin film of residual chlorine sanitizer was trapped in the voids created by the loss of fluoropolymer particles (Zhao and Liu, 2005a), further lowering the apparent contact angle.

Exposure to iodine sanitizer had minimal effect on the contact angle value of native stainless steel and resulted in moderate decrease in contact angle values of Ni-PTFE-modified coupons. Interestingly, the contact angle value of Ni-PTFE-modified coupons fell to $83.1^{\circ}$ after 6 cycles of exposure to iodine-based sanitizer, rendering it more hydrophilic than native steel coupons $\left(\theta_{\mathrm{a}}=93.8^{\circ}\right)$. This result may be due to the presence of phosphoric acid in the iodine sanitizer and is in agreement with a prior report (Barish and Goddard, 2014). Barish and Goddard (2014) reported that acid sanitizer significantly affected Ni-PTFE coatings, in which the concentration of phosphoric acid was approximately $0.294 \%$.

Advancing contact angle of native steel remained stable after exposure to both peroxide- and iodine-based sanitizers. The observed minor decrease in receding contact angels of native steel after exposure to peroxide sanitizers may be a result of formation of a thin layer of mixed metal oxides on the surface, as proposed by Miyazawa et al. (2006). Even after 168 cycles of exposure to peroxide sanitizer, Ni-PTFE-modified steel remained hydrophobic at approximately $90^{\circ}$, the highest retention of hydrophobicity among all 4 sanitizing agents.

Surface Energy. Surface energy represents an important metric in quantifying nonfouling character in equipment coatings and was calculated using the Neumann model at intervals up to 168 cycles of exposure to the 4 sanitizers (Tavana and Neumann, 2007; Figure 3). As prepared, Ni-PTFE-modified stainless steel exhibited a critical surface energy of $24.42 \mathrm{mN} / \mathrm{m}$, which is in the accepted fouling release range of 20 to $30 \mathrm{mN} / \mathrm{m}$ (Baier, 2006). After exposure to chlorine-based sanitizers, the surface energies of both native and Ni-PTFEmodified steel increased significantly. After 168 cycles 
Native 316 SS

\section{Control}

Sodium hypochlorite

\section{Sodium dichloro-s- triazinetrione}

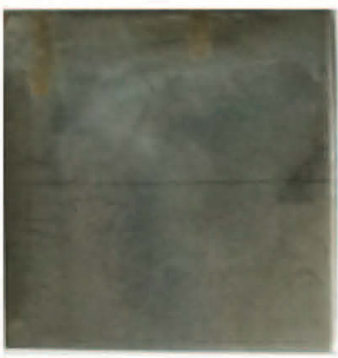

Ni-PTFE 316 SS
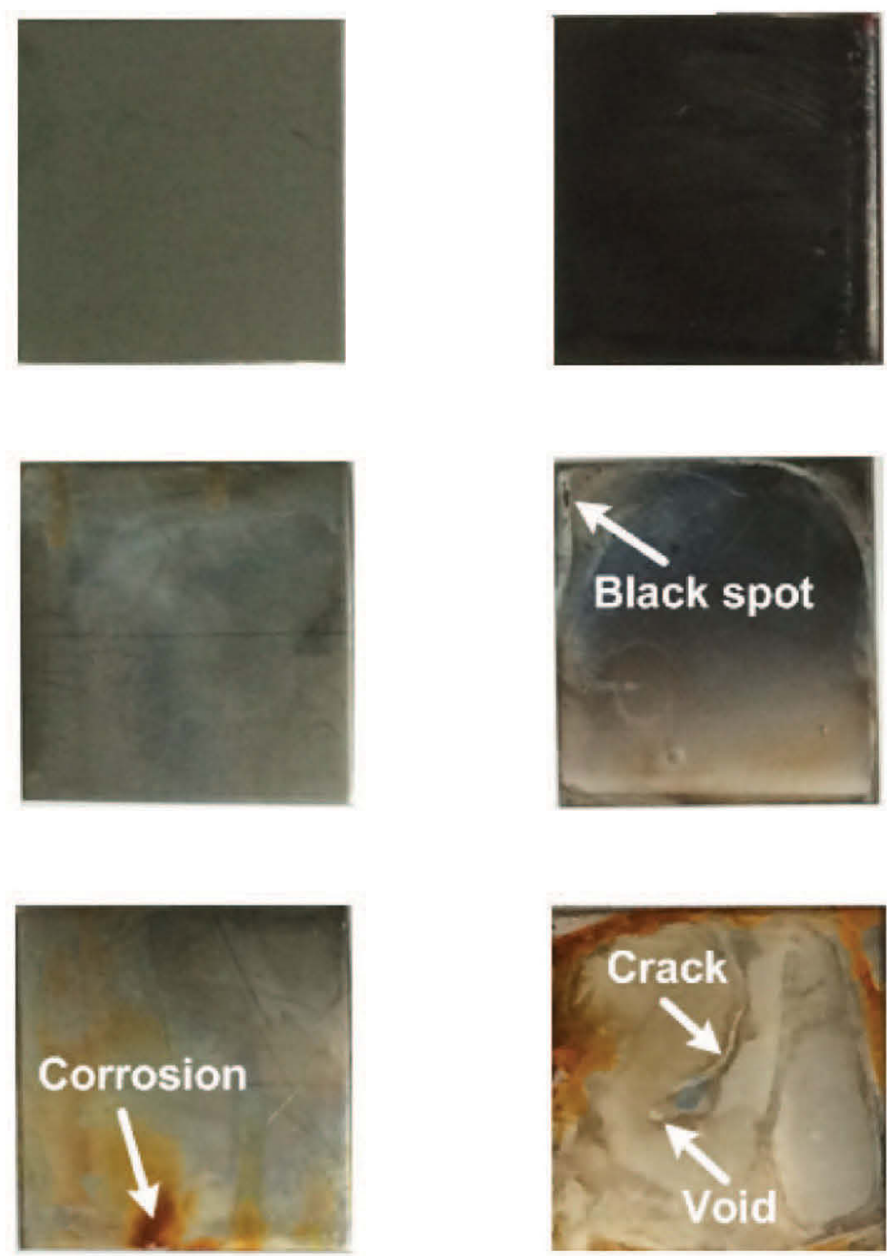

lodine
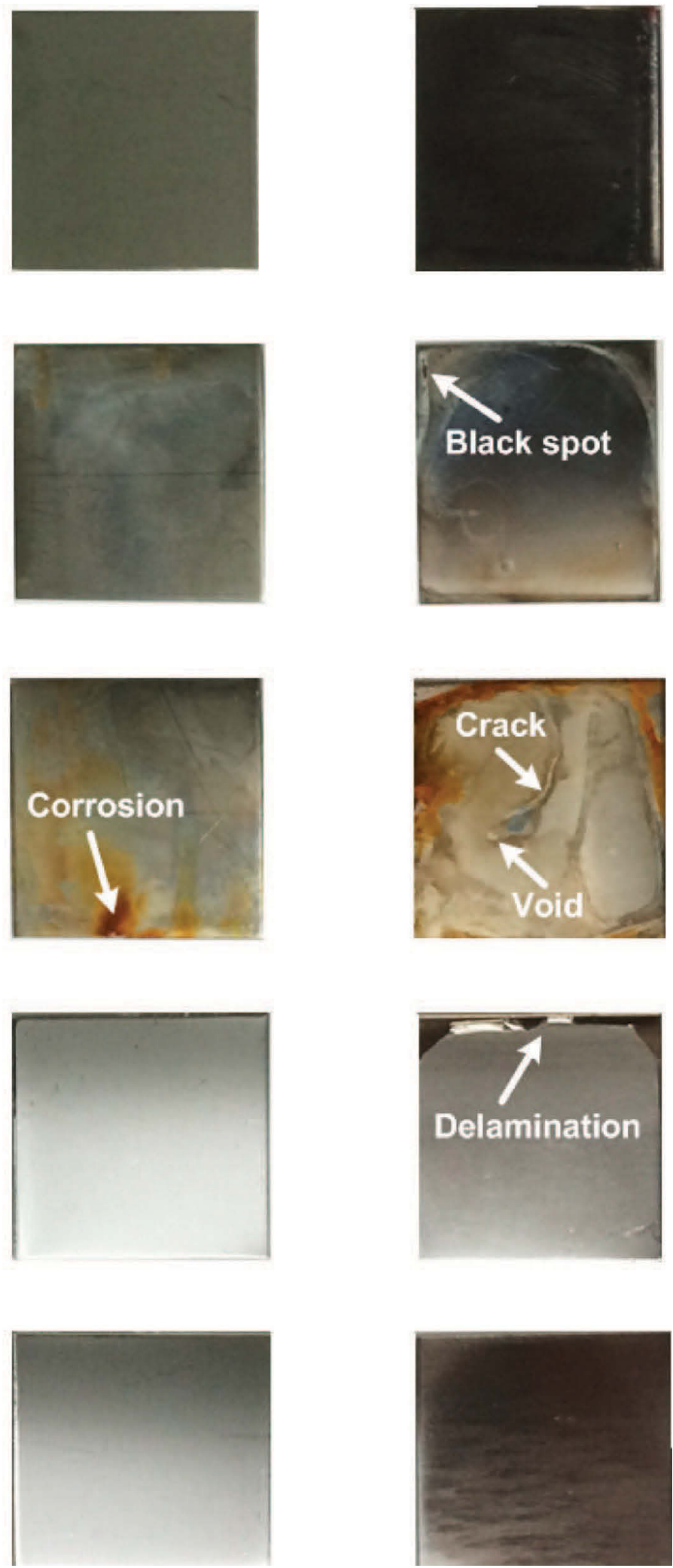

Figure 1. Representative photograph of native (top) and Ni-polytetrafluoroethylene (PTFE)-modified (bottom) surfaces after 168-cycle exposure to 4 commercial food-grade sanitizers. Color version available online. 
Advancing

$\infty$ Receding

A

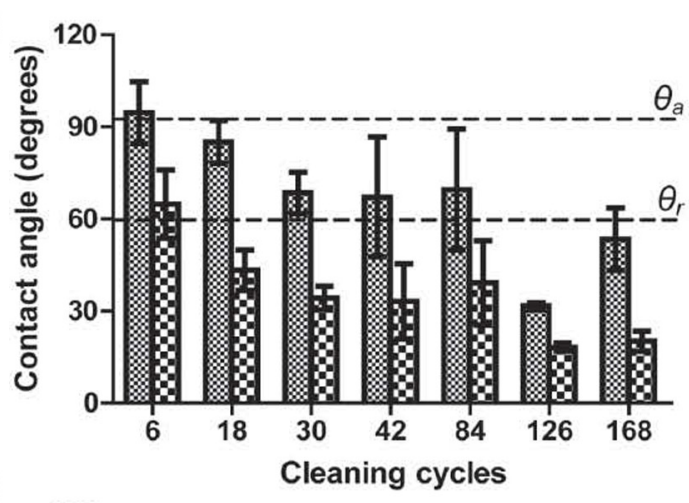

C

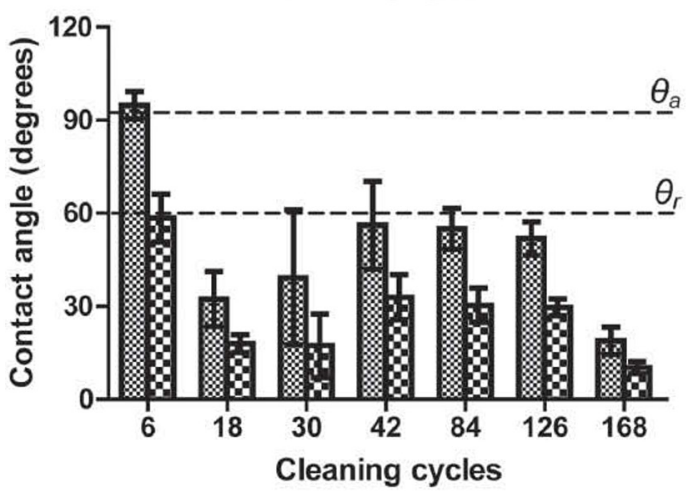

E

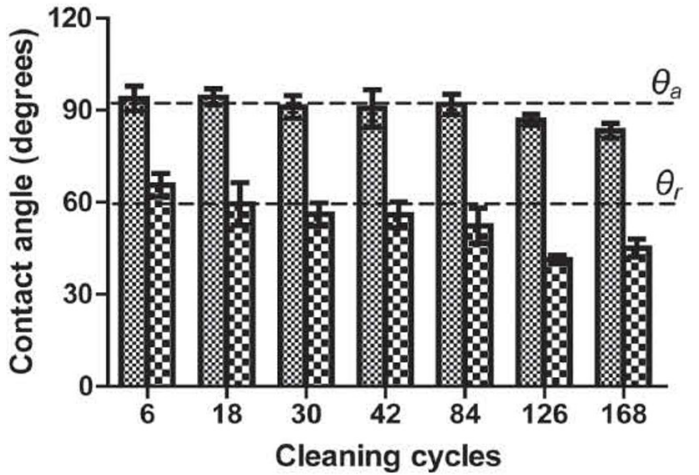

G

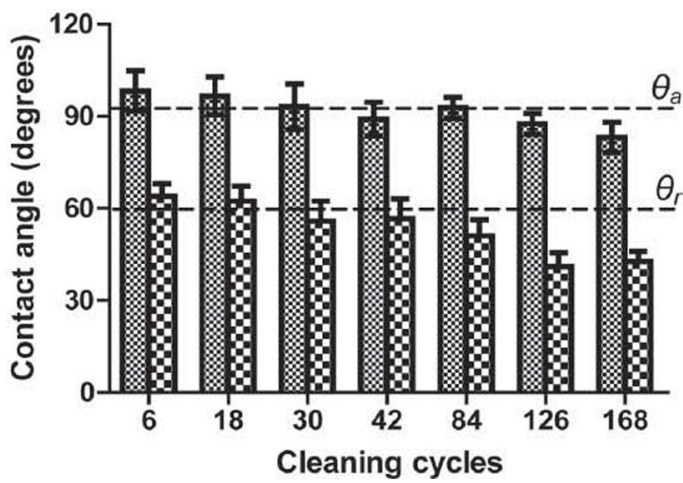

B
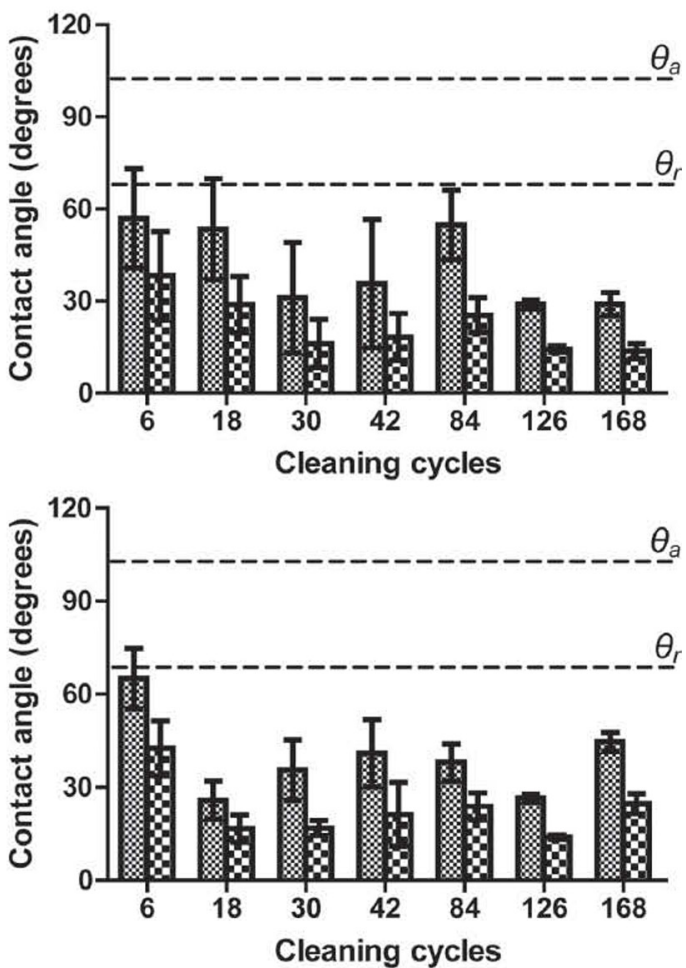

$\mathrm{F}$

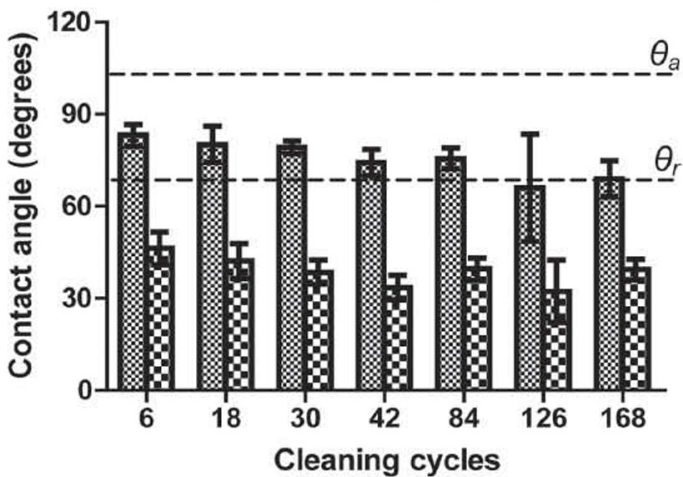

$\mathrm{H}$

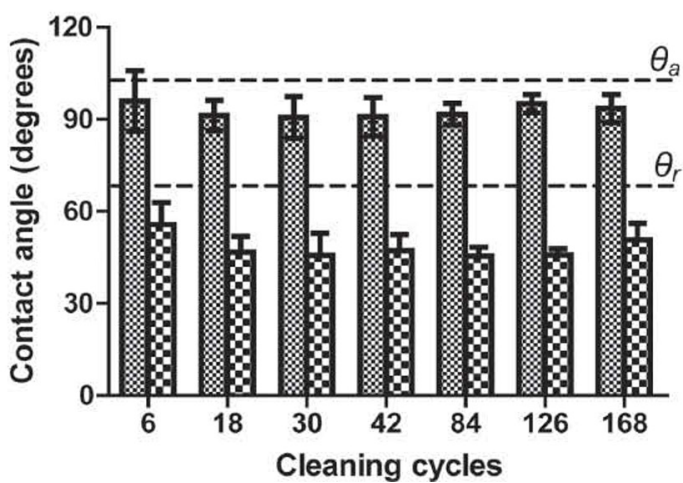

Figure 2. Advancing and receding dynamic contact angle of native (left) and Ni-polytetrafluoroethylene (PTFE)-modified (right) coupons after exposure to food-grade sanitizers: sodium hypochlorite (A and B); sodium dichloro-s-triazinetrione (C and D); iodine (E and F); and peroxide $(\mathrm{G}$ and $\mathrm{H})$. Horizontal lines represent the average advancing (top) and receding (bottom) contact angle values for stainless steel before exposure to sanitizers. Error bars represent SD of $n=9$ values. 
of exposure to sodium hypochlorite, the surface energies of native and modified coupons were $42.80 \pm 0.35$ and $49.06 \pm 0.44 \mathrm{mN} / \mathrm{m}$, respectively. For sodium dichloros-triazinetrione, surface energy of native and modified steel increased to $48.93 \pm 0.72$ and $47.9 \pm 0.65 \mathrm{mN} / \mathrm{m}$, respectively. Although chlorine-based sanitizers are recommended for sanitization of stainless steel surfaces in dairy processing (Northeast Dairy Practice Council, 1993), long-term exposure can result in a significant increase of surface energy due to chloride-induced corrosion (Ayebah and Hung, 2005) as well as dissolution of chromium from the alloy which can accelerate rust formation. The change of surface energy of coupons exposed to iodine sanitizer exhibited a similar trend with that of contact angle. No significant change in surface energy of native coupons was noted after 168 cycles of exposure to iodine-based sanitizer. However, the surface energy values of modified coupons increased with the number of cleaning cycles. After 168 cycles of exposure to iodine sanitizers, the surface energy of modified coupons was $36.44 \pm 0.32 \mathrm{mN} / \mathrm{m}$, similar to that of native steel coupons $(33.82 \pm 1.67 \mathrm{mN} / \mathrm{m})$. Finally, no significant change in surface energy values of native or Ni-PTFE-modified steel surfaces was observed after 168 cycles of exposure to peroxide sanitizer, which is in agreement with the observations above on the water contact angle values.

XPS Analysis. X-ray photoelectron spectroscopy was performed to characterize the elemental composition in the top $\sim 5 \mathrm{~nm}$ of the coupons' surfaces (Yfantis et al., 1999; Table 2). Elemental composition (F 1s, Ni 2p, P 2p, O 1s, C 1s, Fe 2p, and Cr 2p, in which 1s and $2 \mathrm{p}$ refer to electron orbital notation) of Ni-PTFE-modified steel (as prepared and after sanitizer exposure) was calculated from survey scans and were reported as atomic percentages in Table 2 .

Atomic percentage of fluorine (present from the embedded PTFE nanoparticles) was $40.6 \%$ in as-prepared Ni-PTFE-modified steel, and decreased after exposure to all 4 sanitizer types. After exposure to either chlorine-based sanitizer, Ni-PTFE-modified surfaces
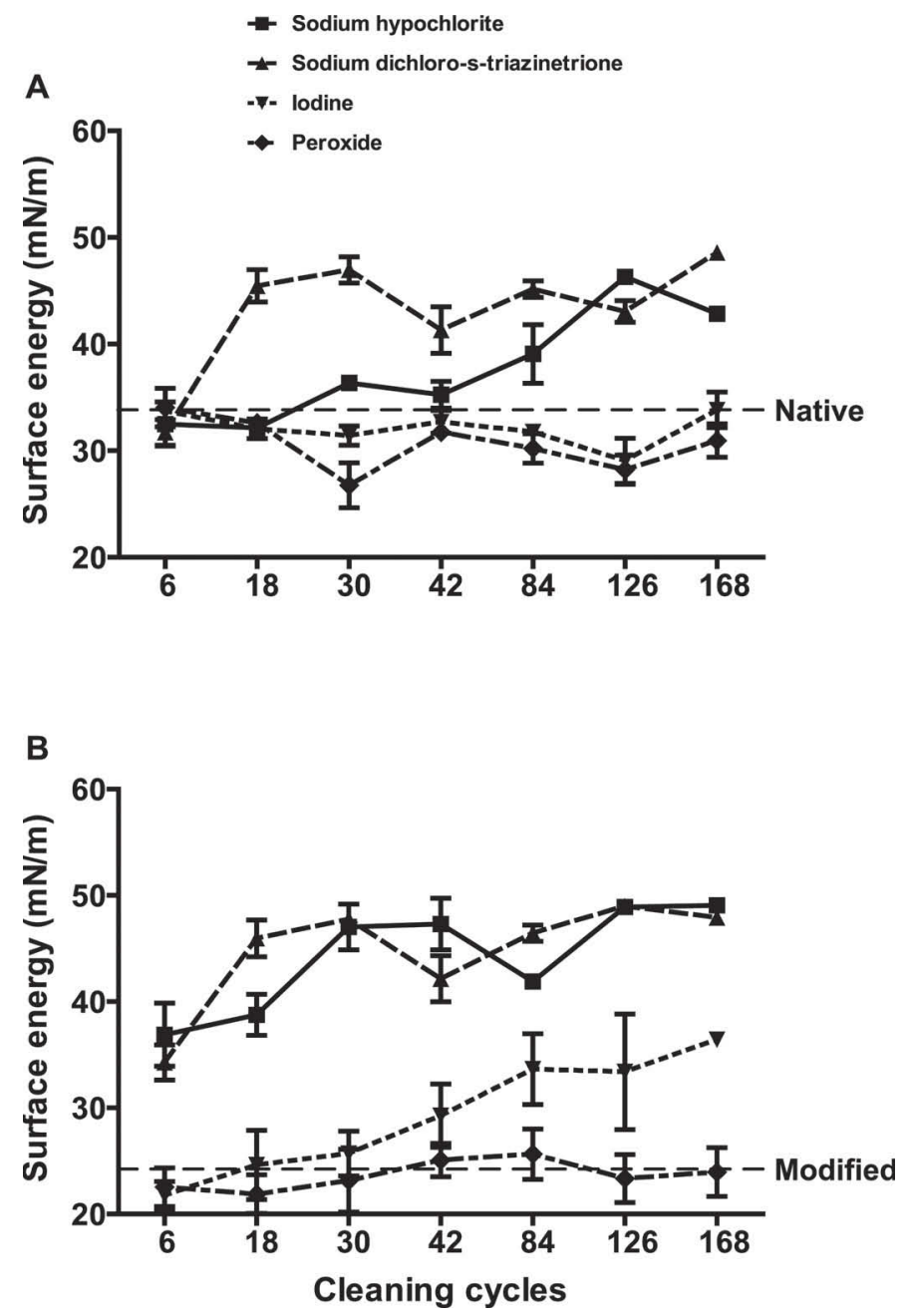

Figure 3. Critical surface energy of native (A) and Nipolytetrafluoroethylene (PTFE)-modified (B) stainless steel coupons after exposure to food-grade sanitizers. Dashed lines represent the critical surface energy of as-prepared native and Ni-PTFE-modified coupons before exposure with error bars representing SD of $n=3$ values.

presented less than $0.1 \%$ at fluorine, suggesting loss of PTFE nanoparticles that were embedded only in the top layer of Ni-P matrix (Rossi et al., 2003). A similar

Table 2. Elemental composition of Ni-polytetrafluoroethylene modified stainless steel before and after 168-cycle exposure to sanitizers as determined by x-ray photoelectron spectroscopy

\begin{tabular}{|c|c|c|c|c|c|c|c|}
\hline Sanitizer & \multicolumn{7}{|c|}{ Atomic composition $^{1}(\%)$} \\
\hline Control & $40.6 \pm 0.9^{\mathrm{c}}$ & $3.6 \pm 0.3^{\mathrm{e}}$ & $3.1 \pm 0.7^{\mathrm{d}}$ & $17.2 \pm 0.2^{\mathrm{d}}$ & $30.9 \pm 0.6^{\mathrm{a}}$ & $4.6 \pm 0.3^{\mathrm{a}}$ & $<0.1$ \\
\hline Sodium dichloro-s-triazinetrione & $<0.1$ & $7.5 \pm 0.4^{\mathrm{c}}$ & $13.8 \pm 0.8^{\mathrm{b}}$ & $53.5 \pm 2.1^{\mathrm{c}}$ & $16.0 \pm 0.2^{\mathrm{c}}$ & $2.5 \pm 0.3^{\mathrm{c}}$ & $6.7 \pm 0.3^{\mathrm{a}}$ \\
\hline Iodine & $1.9 \pm 0.2^{\mathrm{b}}$ & $11.6 \pm 0.2^{\mathrm{b}}$ & $14.0 \pm 0.8^{\mathrm{b}}$ & $40.9 \pm 1.6^{\mathrm{b}}$ & $21.7 \pm 0.4^{\mathrm{b}}$ & $9.5 \pm 0.4^{\mathrm{b}}$ & $<0.1$ \\
\hline Peroxide & $9.9 \pm 0.9^{\mathrm{a}}$ & $15.0 \pm 0.1^{\mathrm{a}}$ & $5.8 \pm 0.1^{\mathrm{a}}$ & $32.8 \pm 0.7^{\mathrm{a}}$ & $32.5 \pm 0.8^{\mathrm{a}}$ & $4.1 \pm 0.8^{\mathrm{a}}$ & $<0.1$ \\
\hline
\end{tabular}

${ }^{\mathrm{a}-\mathrm{e}}$ Values in the same column with the same letter are not significantly different $(P>0.05)$.

${ }^{1} 1 \mathrm{~s}$ and $2 \mathrm{p}$ refer to electron orbital notation. 
conclusion was reported by prior studies (Zhao and Liu, 2005a,b), in which the PTFE particles were released from the Ni-P matrix during a corrosion test in a chlorinated solution. In the work of Zhao and Liu (2005a), Ni-P-based coatings (among others) were characterized for corrosion behavior after extended exposure to either hydrochloric acid or sodium chloride solutions and it was observed that chloride solutions cause corrosion in electroless Ni-P coatings. This corrosive behavior is enhanced at low $\mathrm{pH}$ value of the mineral acid, hydrochloric acid. Our previous study also indicated a decrease of PTFE content on the Ni-PTFE-modified surface after exposure to acid sanitizer (Barish and Goddard, 2014). The observed loss of PTFE nanoparticles is in agreement with the results of decreasing contact angle and increasing surface energy values. After exposure to iodine and peroxide sanitizers, fluorine content decreased to 1.9 and $9.9 \%$, respectively. These results further confirm that peroxide sanitizer has the least effect on the Ni-PTFE coatings. As fluorine content decreased with exposure to chlorine- and iodine-based sanitizers, phosphorus content increased, suggesting failure of the coatings. The detectable chromium content in Ni-PTFE-modified steel after exposure to sodium dichloro-s-triazinetrione sanitizer further suggests delamination of the coating. Increasing surface oxygen percentage supports our conclusion of oxide formation noted above. Despite no visual evidence of oxide formation after exposure to iodine and peroxide sanitizers, the increase in surface oxygen suggests that some oxide formation in these samples as well. Such oxide formation may contribute to the reduction in fluorine content, as even nanoscale oxide growth would reduce the fluorine content of the region of interrogation by XPS.

Electron Microscopy. Scanning electron microscopy was used to evaluate changes in surface morphology on the modified Ni-PTFE stainless steel both as prepared (Figure 4) and after exposure to different sanitizers (Figure 5). Polytetrafluoroethylene nanoparticles with the diameter of $200 \mathrm{~nm}$ were evident as small dark spots embedded in Ni-P matrix.

After just 6 cycles of exposure to chlorinated sanitizers, evident change was observed in surface morphology. Discrete particles became blurred, suggesting failure of plated Ni-P matrix, and evidence of redeposition of failed coating was noted (Figure 5). After 168 cycles of exposure to chlorine-based sanitizers, the degradation of the coatings was severe, including nonuniform distribution of PTFE particles and evidence of delamination. From the micrograph of coupons after 168 cycles of exposure to sodium dichloro-s-triazinetrione, some dark spots with the diameter of $2 \mu \mathrm{m}$ were observed, likely a result of corrosion on the surface. This observation was in agreement with XPS results, in which it was demonstrated that exposure to chlorinated sanitizers led to the highest oxygen content in the top surface of modified coupons.

After 6 cycles of exposure to iodine and peroxide sanitizers, no visual difference from the as-prepared coupons was observed, according to not only the distribution of the embedded PTFE nanoparticles, but also the color and size. Extended exposure to iodine-based sanitizers resulted in larger and less discreet dark spots, likely a result of particle loss and subsequent erosion of the particle cavities by phosphoric acid in the sanitizer. The Ni-PTFE-modified steel retained uniform particle distribution after even 168-cycle exposure to peroxide sanitizers.

\section{Fouling Experiments}

The fouling behavior of Ni-PTFE-modified coupons after 168-cycle exposure to sanitizers was characterized by pasteurization of raw milk for $2 \mathrm{~h}$ on a custom bPHE apparatus, in which Ni-PTFE-modified steel served as the heat transfer surface. After each experimental run, test coupons were weighed without rinsing or cleaning. The weight difference of foulant accumulated on heat exchanger plates was calculated before and after simulated pasteurization of raw milk (Figure 6). The amount of foulant accumulated on native and as-prepared NiPTFE-modified coupons are represented by horizontal dashed lines and were $2.64 \pm 0.48$ and $6.81 \pm 0.48 \mathrm{mg} /$ $\mathrm{cm}^{2}$, respectively. Exposure to chlorine-based sanitizers had the greatest effect on nonfouling character, with

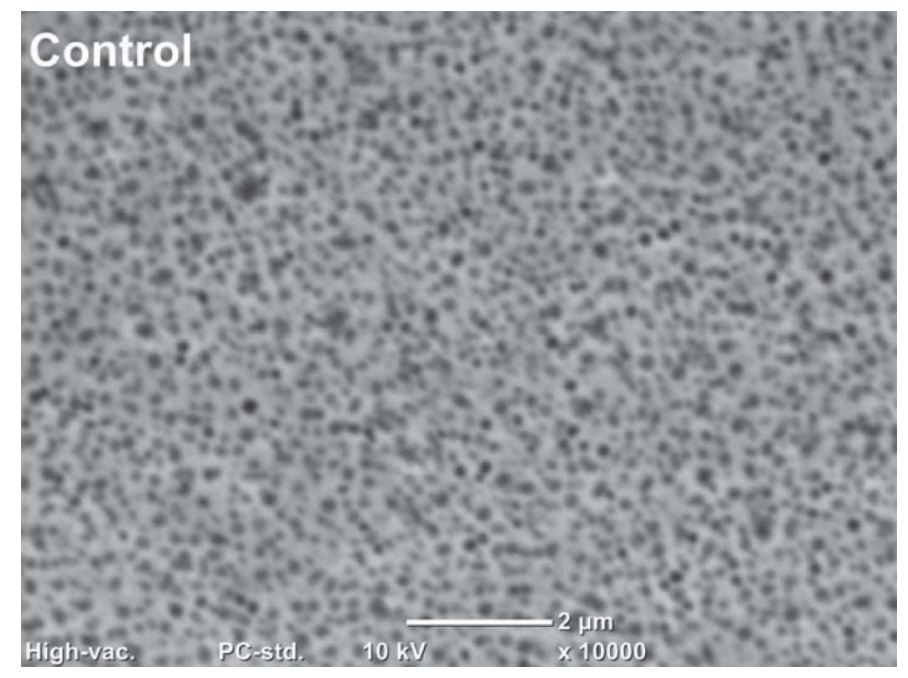

Figure 4. Electron micrograph of as-prepared Nipolytetrafluoroethylene (PTFE)-modified stainless steel coupons. 

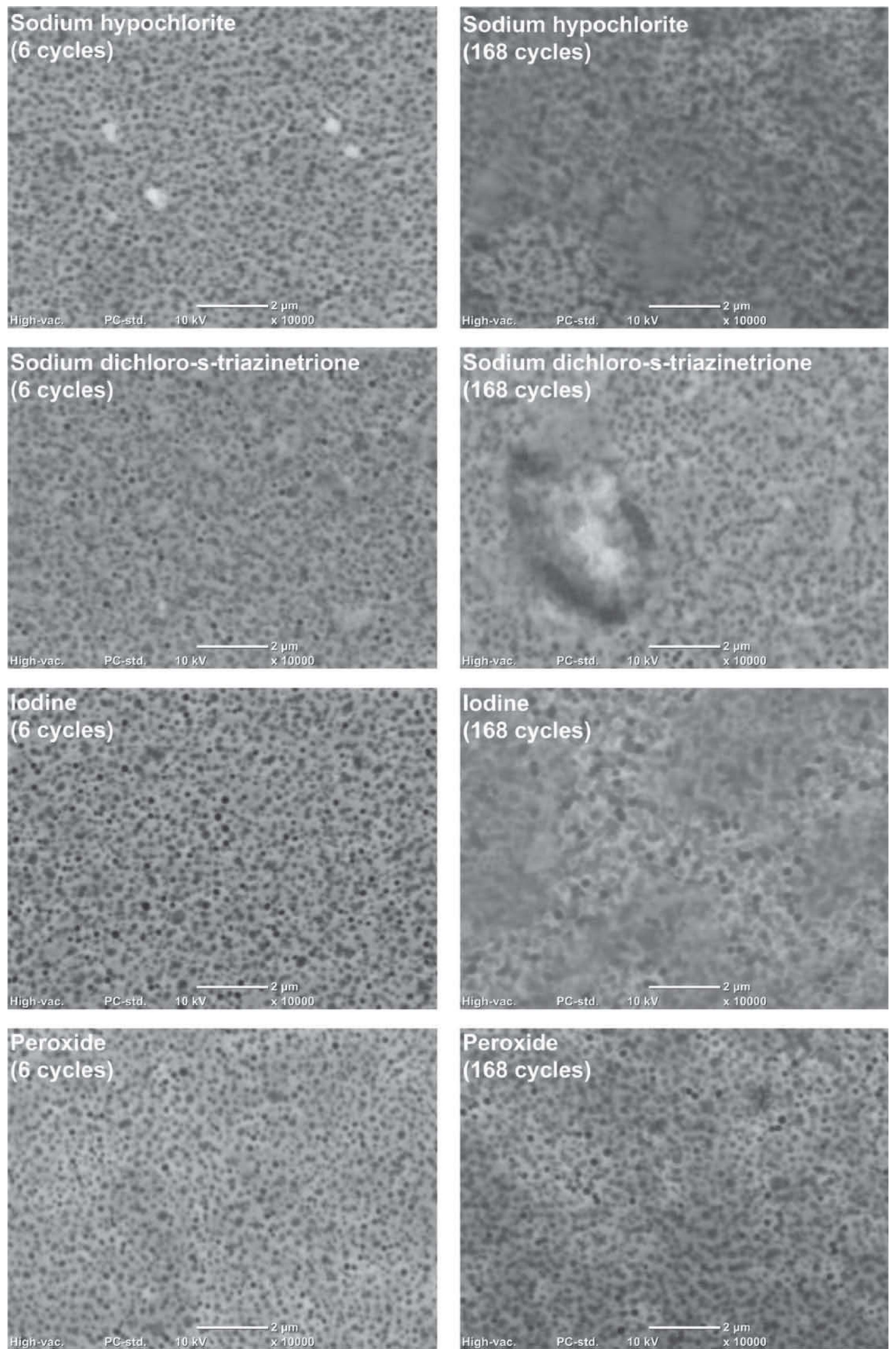

Figure 5. Electron micrographs of Ni-polytetrafluoroethylene (PTFE)-modified stainless steel coupons after 6- and 168-cycle exposure to sanitizers. 


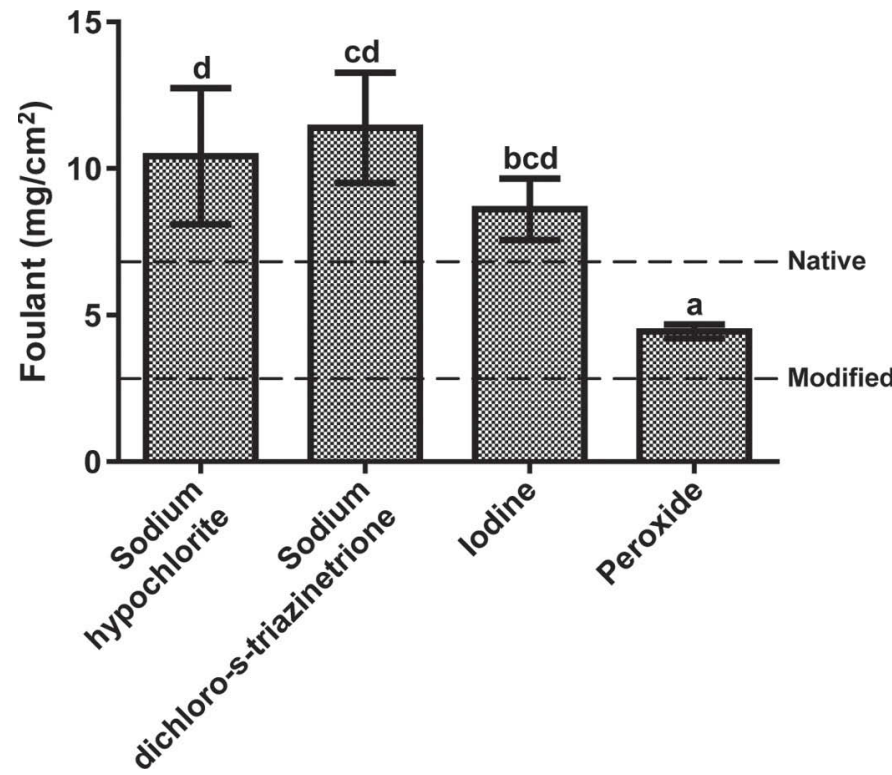

Figure 6. Weight of foulant accumulated after processing of raw milk $\left(2 \mathrm{~h}, 85^{\circ} \mathrm{C}, 5 \mathrm{~L} / \mathrm{h}\right)$ on coupons after 168 -cycle exposure to sanitizers. Dashed lines represent the amount of foulant accumulated on the as-prepared native (top) and Ni-polytetrafluoroethylene-modified (bottom) coupons before exposure. Values with the same letter (a-d) are not significantly different $(P>0.05)$ with error bars representing the $\mathrm{SD}$ of $\mathrm{n}=3$ values.

foulant accumulations of 10.41 and $11.39 \mathrm{mg} / \mathrm{cm}^{2}$ after exposure to hypochlorite- and dichloro-s-triazinetrionebased sanitizers, respectively. The amount of foulant accumulated on Ni-PTFE-modified steel after extended exposure to peroxide-based sanitizers was greater than that of as-prepared Ni-PTFE-modified steel (4.44 $\pm 0.24 \mathrm{mg} / \mathrm{cm}^{2}$ ), but remained below the amount of foulant accumulated on native steel surfaces under the same processing conditions.

Because of its importance in heat transfer efficiency, thickness of fouling material accumulated on the coupons was measured by optical profilometry (Figure 7). The average value of thickness of fouling material accumulated on the modified coupons before exposure was $40.94 \pm 24.55 \mu \mathrm{m}$. An increased thickness of fouling material was observed from coupons after exposure to commercial sanitizers, which is in agreement with the trend observed as a result of the weight of fouling material. The coupons exposed to sodium dichloro-striazinetrione exhibited the greatest thickness of fouling material $(176.25 \pm 19.62 \mu \mathrm{m})$. The thinnest fouling material $(81.77 \pm 16.02 \mu \mathrm{m})$ was observed from the coupons after exposure to peroxide sanitizer, which was still less than the foulant thickness on the native coupons $(102.46 \pm 5.32 \mu \mathrm{m})$.

A major hurdle to commercial adoption of nonfouling coatings to dairy processing equipment is the charac- terization of their stability against sanitizers commonly used in equipment sanitization (e.g., chlorine-, iodine-, and peroxide-based sanitizers). Indeed, it is expected that the nature of each coating technology (e.g., chemistry, method of application) will influence its stability. The results of this work suggest that electroless NiPTFE coatings are robust against extended exposure to peroxide-based sanitizers and retain low surface energy, high water contact angle values, and ability to resist fouling during thermal processing of fluid milk as quantified by foulant weight and thickness.

\section{CONCLUSIONS}

The objective of the present study was to evaluate the effect of a range of sanitizers approved for food contact surface application on the stability of nonfouling Ni-PTFE coatings. Nickel-PTFE-coated 316 stainless steel coupons were exposed to commercially available chlorine-, iodine-, and peroxide-based sanitizers and characterized for surface properties and retention of nonfouling character. Surface properties including dynamic contact angle, surface energy, morphology, and elemental composition were measured before and after the coupons were exposed to the sanitizers for 168 cleaning cycles. The fouling behavior of modified coupons after exposure to sanitizers was evaluated using a self-

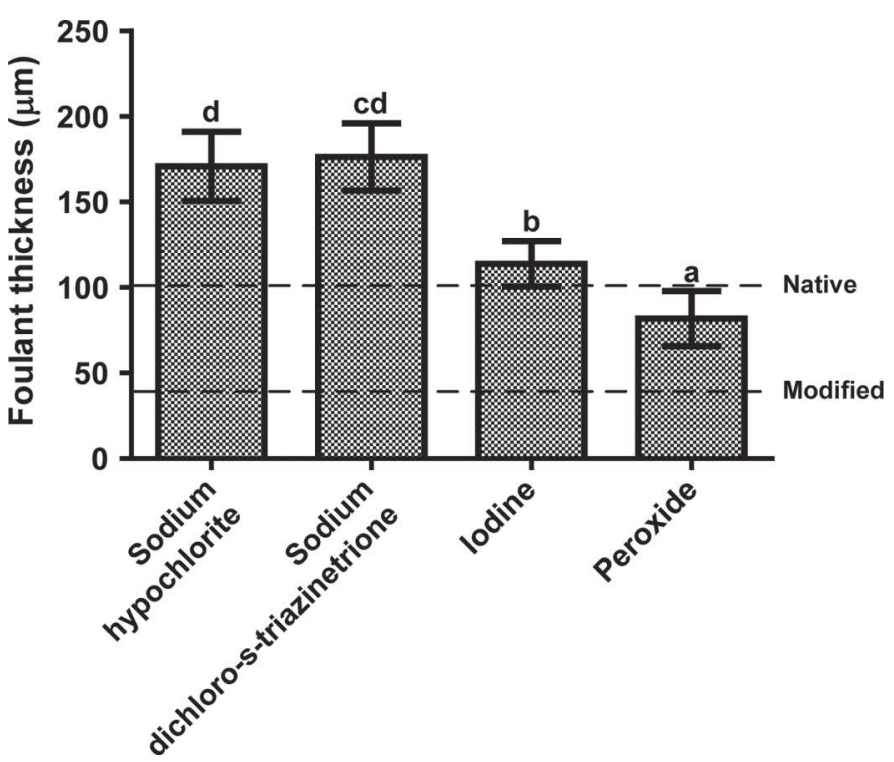

Figure 7. Thickness of foulant after processing of raw milk (2 $\left.\mathrm{h}, 85^{\circ} \mathrm{C}, 5 \mathrm{~L} / \mathrm{h}\right)$ on coupons after 168 -cycle exposure to sanitizers. Dashed lines represent the thickness of foulant accumulated on the as-prepared native (top) and Ni- Ni-polytetrafluoroethylene-modified (bottom) coupons before exposure. Values with the same letter (a-d) are not significantly different $(P>0.05)$ with error bars representing $\mathrm{SD}$ of $\mathrm{n}=9$ values. 
fabricated bPHE system. Results indicated that peroxide-based sanitizers had minor effect on the chemistry, morphology, surface energy, and nonfouling character of Ni-PTFE-modified stainless steel coupons, whereas the other sanitizers (chlorine- and iodine-based) caused significant coating failure. The corrosion observed in native steel coupons after long-term exposure to either chlorine-based sanitizer suggests that chlorine-based sanitizers are not appropriate for routine, long-term use on either modified or native stainless steel. The amount of foulant accumulated on peroxide-exposed Ni-PTFE-coated steel after $2 \mathrm{~h}$ of thermal processing of raw milk was less than that on native stainless steel coupons, which indicated that the Ni-PTFE modification retained nonfouling character even after extended exposure to peroxide sanitizers. These results suggest that stainless steel food processing surfaces modified with nonfouling Ni-PTFE coatings are robust against exposure to peroxide sanitizer and retain antifouling properties. Translational research, such as the stability studies performed herein, are an often overlooked aspect of nonfouling coatings research, but are necessary to enable their commercial adoption. Additional research characterizing the safety and toxicological risks associated with potential migration of coating components (e.g., Ni, P, PTFE particles) must be performed using true food systems and processing conditions to identify food systems for which these coatings are (and are not) appropriate. The results obtained from this study can support proper selection of clean-in-place chemicals for sanitation of food and beverage processing equipment.

\section{ACKNOWLEDGMENTS}

The authors gratefully acknowledge Julian McClements (University of Massachusetts, Amherst) for use of Kruss DSA100 and Thomas McCarthy and Jacob Hirsch (University of Massachusetts, Amherst) for use of their Physical Electronics Quantum 2000 and support in XPS data analysis. This project was supported by Dairy Management Inc., as managed by Dairy Research Institute (Rosemont, IL).

\section{REFERENCES}

Ayebah, B., and Y. Hung. 2005. Electrolyzed water and its corrosiveness on various surface materials commonly found in food processing facilities. J. Food Process Eng. 28:247-264.

Baier, R. E. 2006. Surface behaviour of biomaterials: The theta surface for biocompatibility. J. Mater. Sci. Mater. Med. 17:1057-1062.

Balasubramanian, S., and V. M. Puri. 2009a. Reduction of milk fouling in a plate heat exchanger system using food-grade surface coating. Trans. ASABE 52:1603-1610. http://dx.doi. org/10.13031/2013.29111.
Balasubramanian, S., and V. M. Puri. 2009b. Thermal energy savings in pilot-scale plate heat exchanger system during product processing using modified surfaces. J. Food Eng. 91:608-611.

Bansal, B., and X. D. Chen. 2006. A critical review of milk fouling in heat exchangers. Compr. Rev. Food Sci. Food Saf. 5:27-33.

Barish, J. A., and J. M. Goddard. 2013. Anti-fouling surface modified stainless steel for food processing. Food Bioprod. Process. 91:352-361.

Barish, J. A., and J. M. Goddard. 2014. Stability of nonfouling stainless steel heat exchanger plates against commercial cleaning agents. J. Food Eng. 124:143-151.

Bohner, H. F., and R. L. Bradley. 1991. Corrosivity of chlorine dioxide used as sanitizer in ultrafiltration systems. J. Dairy Sci. 74:3348-3352.

Burton, H. 1968. Reviews of the progress of dairy science. Section G. Deposits from whole milk in heat treatment plant-A review and discussion. J. Dairy Res. 35:317-330.

Combe, E. C., B. A. Owen, and J. S. Hodges. 2004. A protocol for determining the surface free energy of dental materials. Dent. Mater. 20:262-268.

Dumitrascu, N., and C. Borcia. 2006. Determining the contact angle between liquids and cylindrical surfaces. J. Colloid Interface Sci. 294:418-422.

Forster, M., and M. Bohnet. 2000. Modification of molecular interactions at the interface crystal/heat transfer surface to minimize heat exchanger fouling. Int. J. Therm. Sci. 39:697-708.

Gao, L., and T. J. McCarthy. 2009. Wetting 101 . Langmuir 25:1410514115.

Huang, K., and J. M. Goddard. 2015. Influence of fluid milk product composition on fouling and cleaning of Ni-PTFE modified stainless steel heat exchanger surfaces. J. Food Eng. 158:22-29.

Kananeh, A. B., E. Scharnbeck, U. Kuck, and N. Rabiger. 2010. Reduction of milk fouling inside gasketed plate heat exchanger using nano-coatings. Food Bioprod. Process. 88:349-356.

Khadre, and A. E. Yousef. 2001. Sporicidal action of ozone and hydrogen peroxide: A comparative study. Int. J. Food Microbiol. 71:131-138.

Lalande, M., F. Rene, and J. P. Tissier. 1989. Fouling and its control in heat exchangers in the dairy industry. Biofouling 1:233-250.

Long, J., and P. Chen. 2006. On the role of energy barriers in determining contact angle hysteresis. Adv. Colloid Interface Sci. 127:55-66.

Makamba, H., Y. Y. Hsieh, W. C. Sung, and S. H. Chen. 2005. Stable permanently hydrophilic protein-resistant thin-film coatings on poly(dimethylsiloxane) substrates by electrostatic self-assembly and chemical cross-linking. Anal. Chem. 77:3971-3978.

Mittal, K. L. 2006. Contact Angle, Wettability, and Adhesion. CRC Press, Boca Raton, FL.

Miyazawa, T., T. Terachi, S. Uchida, T. Satoh, T. Tsukada, Y. Satoh, Y. Wada, and H. Hosokawa. 2006. Effects of hydrogen peroxide on corrosion of stainless steel, (V) characterization of oxide film with multilateral surface analyses. J. Nucl. Sci. Technol. 43:884-895.

Northeast Dairy Practice Council. 1993. Guidelines for Cleaning and Sanitizing in Fluid Milk Processing Plants. Publication no. 29. NDPC, Syracuse, NY.

Parkar, S. G., S. H. Flint, and J. D. Brooks. 2004. Evaluation of the effect of cleaning regimes on biofilms of thermophilic bacilli on stainless steel. J. Appl. Microbiol. 96:110-116.

Rosmaninho, R., O. Santos, T. Nylander, M. Paulsson, M. Beuf, T. Benezech, S. Yiantsios, N. Andritsos, A. Karabelas, and G. Rizzo. 2006. Modified stainless steel surfaces targeted to reduce fouling - Evaluation of fouling by milk components. J. Food Eng. 80:1176-1187.

Rosmaninho, R., O. Santos, T. Nylander, M. Paulsson, M. Beuf, T. Benezech, S. Yiantsios, N. Andritsos, A. Karabelas, G. Rizzo, H. Müller-Steinhagen, and L. F. Melo. 2007. Modified stainless steel surfaces targeted to reduce fouling-Evaluation of fouling by milk components. J. Food Eng. 80:1176-1187.

Rossi, S., F. Chini, G. Straffelini, P. L. Bonora, R. Moschini, and A. Stampali. 2003. Corrosion protection properties of electroless 
nickel/PTFE, phosphate/MoS2 and bronze/PTFE coatings applied to improve the wear resistance of carbon steel. Surf. Coat. Tech. 173:235-242.

Santos, O., T. Nylander, R. Rosmaninho, G. Rizzo, S. Yiantsios, N. Andritsos, A. Karabelas, H. Müller-Steinhagen, L. Melo, L. Boulangé-Petermann, C. Gabet, A. Braem, C. Trägårdh, and M. Paulsson. 2004. Modified stainless steel surfaces targeted to reduce fouling-Surface characterization. J. Food Eng. 64:63-79.

Sharma, A. K., M. R. Suresh, H. Bhojraj, H. Narayanamurthy, and R. P. Sahu. 1998. Electroless nickel plating on magnesium alloy. Met. Finish. 96:10-16.

Tavana, H., and A. W. Neumann. 2007. Recent progress in the determination of solid surface tensions from contact angles. Adv. Colloid Interface Sci. 132:1-32.

Thouless, M. D. 1991. Cracking and delamination of coatings. J. Vac. Sci. Technol. A 9:2510-2515.

Visser, J., and T. J. M. Jeurnink. 1997. Fouling of heat exchangers in the dairy industry. Exp. Therm. Fluid Sci. 14:407-424.
Yfantis, A., G. Appel, D. Schmeißer, and D. Yfantis. 1999. Polypyrrole doped with fluoro-metal complexes: Thermal stability and structural properties. Synth. Met. 106:187-196.

Zeller, R. III, and L. Salvati Jr. 1994. Effects of phosphorus on corrosion resistance of electroless nickel in 50\% sodium hydroxide. Corrosion 50:457-467.

Zettler, H. U., M. Wei, Q. Zhao, and H. Müller-Steinhagen. 2005. Influence of surface properties and characteristics on fouling in plate heat exchangers. Heat Transf. Eng. 26:3-17.

Zhao, Q., and Y. Liu. 2005a. Comparisons of corrosion rates of Ni-P based composite coatings in $\mathrm{HCl}$ and $\mathrm{NaCl}$ solutions. Corros. Sci. $47: 2807-2815$.

Zhao, Q., and Y. Liu. 2005b. Electroless Ni-Cu-P-PTFE composite coatings and their anticorrosion properties. Surf. Coat. Tech. 200:2510-2514 